\title{
Mohammad Baqer Vosuqi. Remarques sur la pensée politique de l'ayatollah Lārī durant le mouvement constitutionnel
}

Asyeh Ghafourian

\section{(2) OpenEdition}

1 Journals

\section{Édition électronique}

URL : http://journals.openedition.org/abstractairanica/40784

DOI : 10.4000/abstractairanica.40784

ISSN : 1961-960X

Éditeur :

CNRS (UMR 7528 Mondes iraniens et indiens), Éditions de l'IFRI

\section{Édition imprimée}

Date de publication : 1 décembre 2013

ISSN : 0240-8910

\section{Référence électronique}

Asyeh Ghafourian, « Mohammad Baqer Vosuqi. Remarques sur la pensée politique de l'ayatollah Lārī durant le mouvement constitutionnel », Abstracta Iranica [En ligne], Volume 32-33 | 2013, document 299, mis en ligne le 01 juillet 2016, consulté le 03 octobre 2020. URL : http://journals.openedition.org/ abstractairanica/40784; DOI : https://doi.org/10.4000/abstractairanica.40784

Ce document a été généré automatiquement le 3 octobre 2020.

Tous droits réservés 


\title{
Mohammad Baqer Vosuqi. Remarques sur la pensée politique de l'ayatollah Lārī durant le mouvement constitutionnel
}

\author{
Asyeh Ghafourian
}

\section{RÉFÉRENCE}

Mohammad Baqer Vosuqi. « Remarques sur la pensée politique de l'ayatollah Lārī durant le mouvement constitutionnel ", in : Denis Hermann, Sabrina Mervin, éds., Courants et dynamiques chiites à l'époque moderne (XVIIIe-XXe). Beirut, IFRI et Ergon Verlag Würzburg in Kommission, 2010, p. 171-180.

1 Professeur d'histoire à l'Université de Téhéran et auteur de plusieurs livres et articles sur la région du sud de l'Iran, M. B. Vosuqi consacre cet article à la vie et la pensée d'Āyatollāh Lārī pendant le mouvement constitutionnel. Dans un précédant article («Ayatollah Seyyed Abdolhossein Lâri et son 'manifeste pour la défense' (1915)», in : Etudes réunies et présentées par Oliver Bast, La Perse et la Grande Guerre, Téhéran, IFRI, 2002) il avait déjà abordé le rôle joué par ce religieux influent lors de la Grande Guerre en Iran.

2 Disciple de Mīrzā Ḥasan Šīrāzī, Âyatollāh Seyyed 'Abd al-Ḥoseyn Lārī, quitte Najaf, la ville où il étudiait la théologie, pour s'installer à Lār, où il sera soutenu, à la fois sur le plan moral et financier, par des notables locaux. Il a publié de nombreux traités juridiques, mais les événements politiques de son époque et son intérêt personnel pour la politique, font qu'il interviendra aussi sur le sujet politique.

3 Āyatollāh Lārī fait de son engagement un acte obligatoire vis à vis de la religion et considère que la constitution doit obéir au droit islamique. A ses yeux, l'équité est affaire des religieux, c'est pourquoi il leur incombe toute fonction de supervision. Dans 
ses traités il fait appel à la mobilisation du peuple contre les oppresseurs qui gouvernent l'Iran ainsi que les étrangers usurpateurs.

4 Le principal intérêt de cet article est que l'A., à travers le cas d'Āyatollāh Lārī, nous démontre que tous les religieux n'étaient pas anti-constitutionnalistes. Probablement par manque de sources et avec un regard binaire, les religieux étaient considérés comme des « anti-constitutionnalistes" et les non religieux des «proconstitutionnalistes ». Ce texte démontre que certains Oulémas pouvaient partager les idées des constitutionnalistes.

\section{AUTEURS}

\section{ASYEH GHAFOURIAN}

Bulac, Paris 